\title{
INFLUENCE OF HOT BURNED GAS UTILIZATION ON THE EXHAUST EMISSION CHARACTERISTICS OF A CONTROLLED AUTO-IGNITION TWO-STROKE CYCLE ENGINE
}

\author{
A.M. Andwari", A.A. Aziz, M.F.M. Said, Z.A. Latiff and A. Ghanaati \\ Automotive Development Center (ADC) \\ Faculty of Mechanical Engineering \\ Universiti Teknologi Malaysia \\ 81310, Johor Bahru, Malaysia \\ *Email: maamin8@live.utm.my \\ Phone: +(6)07-5535447; Fax: +(6)07-5535811
}

\begin{abstract}
A controlled auto-ignition (CAI) two-stroke cycle engine suggests an exceptional aspect and promising future for internal combustion engines (ICEs), such as a higher power-toweight ratio, higher combustion efficiency and lower exhaust gas emissions. Conventional two-stroke cycle engines emit higher exhaust gas emissions and offer lower fuel saving economy. Most of these drawbacks can be addressed if CAI combustion is associated with a two-stroke cycle engine. An experimental investigation is carried out based on a single-cylinder CAI two-stroke cycle engine using Internal and External Exhaust Gas Recirculation (In-EGR and Ex-EGR) and fuels with different octane numbers to investigate the exhaust emissions characteristics. The experimental results indicate a remarkable improvement in the engine's exhaust gas emissions. The concentration of uHC and CO emissions decreased with application of In/Ex-EGR. However, NOx emission increased with the use of In-EGR.
\end{abstract}

Keywords: Controlled auto-ignition; two-stroke cycle engine; exhaust gas recirculation; octane number; exhaust emission.

\section{INTRODUCTION}

In recent years controlled auto-ignition (CAI) combustion has become a new kind of alternative combustion concept, which represents higher thermal efficiency, cleaner exhaust emissions, and lower cyclic variation of internal combustion engines [1-8]. Similar to a conventional SI engine, in a CAI engine the fuel and air are mixed together and then the premixed fuel and air mixture will be compressed. Towards the end of the compression stroke, combustion is initiated by auto-ignition in a similar way to the conventional CI engine [9-11]. Due to the lower combustion peak temperature, NOx (nitric oxide) will be dramatically reduced, while the mixture will be in an ultra-lean fuel-air condition [12-18], and thus be able to achieve high efficiency and low emission. One problem with conventional two-stroke engines is that they produce high levels of unburned hydrocarbons (uHC) because of their unstable operation at low loads [19-21]. However, depending on the engine speed, the equivalence ratio and the quantity of combustion product either via exhaust gas recirculation (EGR) or trapped residual gases, it is possible to introduce auto-ignition combustion in two-stroke engines [22-26]. This combustion process can reduce emissions of uHCs and allow stable engine operation by lower cyclic variation $[11,13]$. In order to achieve auto-ignition at the end 
of the compression stroke, the temperature of the charge at the beginning of the compression $\left(T_{e p c}\right)$ stroke should be sufficiently high [25-29]. Deployment of EGR results in a higher gas temperature throughout the compression process, which in turn speeds up the chemical reactions and eventually leads to the start of auto-ignition combustion of the homogeneously mixed fuel and air mixture [10, 11, 29, 30]. These requirements can be realized whether using In-EGR or Ex-EGR. In general, the main influence of EGR application on combustion characteristics can be summarized as follows:

Hot burned gases increase the temperature of the intake charge owing to their heating effect (Charge Heating Effect). The burned gases replace the air/oxygen (Dilution Effect). Due to the existence of some species in burned gases (e.g. carbon dioxide $\mathrm{CO}_{2}$ and water vapor $\mathrm{H}_{2} \mathrm{O}$ ), the heat capacity of the cylinder charge becomes higher (Thermal Effect). The chemical reaction will increase due to the participation of some activated radical species (Chemical Effect) [9, 27, 30-33]. Since all researches to date have focused on the effect of internal EGR rather than external EGR in terms of CAI two-stroke engines, this study aims at a new area of research, to examine the effect of external EGR compared with internal EGR changes on the exhaust emission characteristics of a two-stroke engine converted into CAI mode.

\section{DESIGN OF EXPERIMENT AND METHODOLOGY}

\section{Engine Instrumentation and Retrofitting}

A conventional single-cylinder, $150 \mathrm{cc}$ displacement, two-stroke, naturally aspirated, liquid-cooled engine was adopted to be fundamentally modified in order to meet the CAI experimental engine test rig requirements. The engine control unit (ECU) regulates the injector's pulse width module (PWM) in order to tune up the engine's air-to-fuel ratio [34]. In addition, the fuel injection system is equipped with a closed loop lambda control system to monitor the engine's real time AFR.

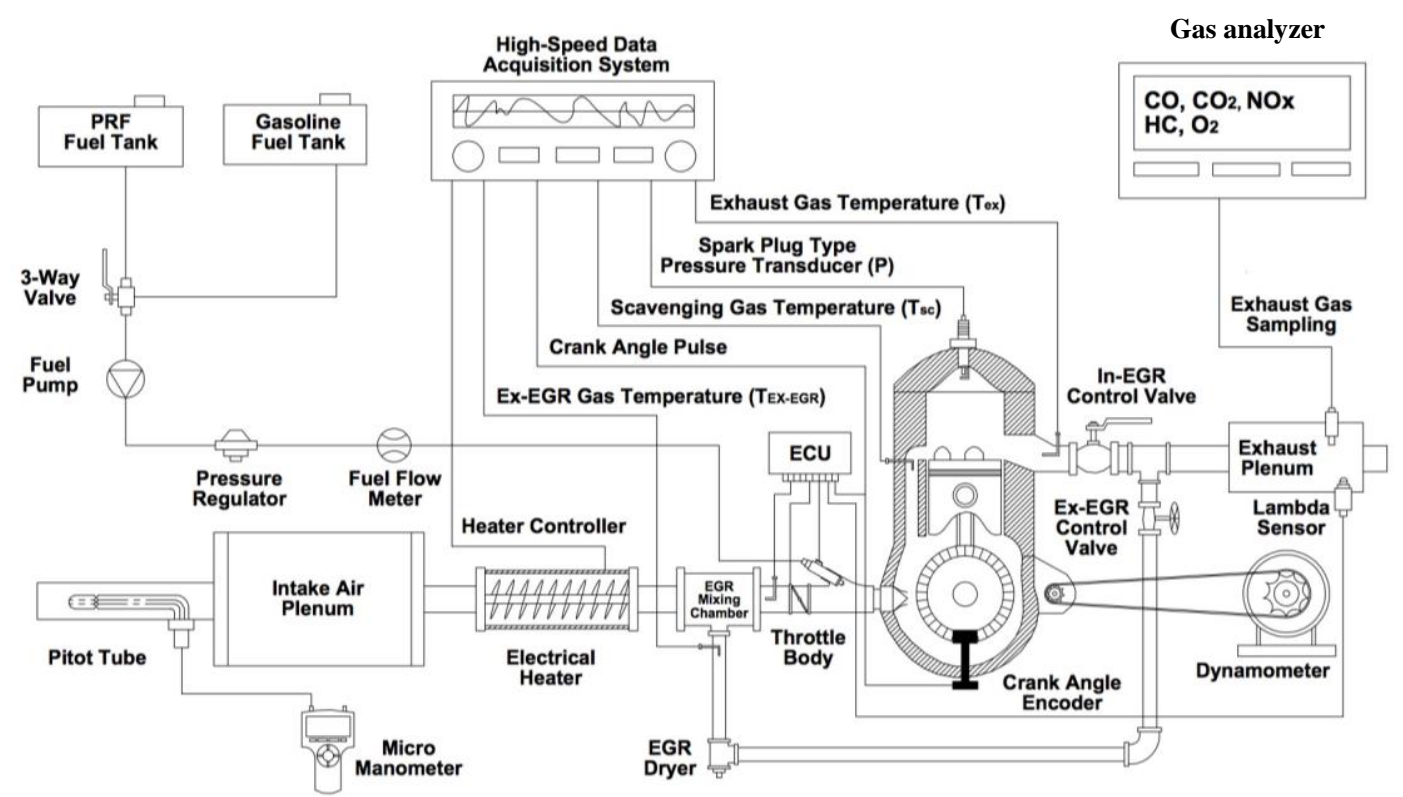

Figure 1. Schematic view of experimental CAI two-stroke cycle engine test rig. 
In order to estimate the engine air consumption, a Pitot tube is installed in conjunction with a micro manometer. The intake charge flow temperature can be adjusted by means of the electric heater temperature controller device. The engine's exhaust piping architecture is developed to be able to utilize some portions of the combustion product for the next consecutive cycle. Accordingly, both In-EGR and ExEGR methods can be employed in order to induce the CAI combustion (see Figure 1). A valve, which is mounted right after the exhaust pipe connection, is able to throttle the exhaust gas, which is called In-EGR, while a bypass pipeline is connected between the exhaust and intake pipe in order to supply some portion of hot burned gas into the intake fresh charge, which is called Ex-EGR. As illustrated in Figure 1, K-type thermocouples $\left( \pm 1^{\circ} \mathrm{C}\right.$ accuracy) are implemented in the specified place to measure the $T_{e x}, T_{i n}$ and $T_{s c}$, which are the engine exhaust gas temperature, intake gas temperature and transfer port gas temperature respectively. A spark plug type piezoelectric pressure transducer (KISTLER 6117B) is used to replace an ordinary spark plug in order to record the engine cycle pressure history. The engine crankshaft is coupled to a crank angle encoder (KISTLER 2613B) to measure the engine crank angle degree (CAD) with 0.2 degrees of resolution. A high-speed data acquisition system called DEWE5000, which is connected to DEWESoft and DEWECa software, is used to log the data. The engine is connected to an eddy-current brake dynamometer (30 kW MAGTROL) via a chain and sprockets since the engine's speed and load need to be controlled properly. Engine fuel consumption is measured by using an in-line type fuel flow sensor (ONO SOKKI FP2240HA). In order to analyze the engine emission output, a portable exhaust gas analyzer (EMS 5002) is employed to acquire the concentration of the $\mathrm{HC}, \mathrm{CO}, \mathrm{NO}_{\mathrm{X}}$ and $\mathrm{CO}_{2}$.

\section{Experimental Procedure and Considerations}

The engine is set to maintain the desired constant load and constant speed by means of the injector PW and dynamometer while the throttle is at the wide open throttle (WOT) position. Once the engine is sufficiently warmed up and the CAI combustion has reached a stable state, the spark is turned off and testing can commence. The engine can be run on lean and ultra-lean mixtures $(\mathrm{AFR}=16-20)$, depending on how much $\mathrm{In} / \mathrm{Ex}$ EGR is applied. For each variation of the In/Ex EGR and the AFR, all of the data are recorded. For each steady state test point, in-cylinder pressure traces from 200 consecutive engine cycles with 0.2 CAD resolutions are recorded for each experimental point. Throughout the experimental procedure, the fuel octane number (ON) can be controlled by blending iso-octane and $n$-heptane and is designated as the primary reference fuel (PRF). The fuel octane numbers range from 0 (100\% n-heptane) to 100 (100\% iso-octane), in accordance with the volume fractions. In this study, the fuels are pre-blended in four combinations, designated as PRF 0, PRF 30, PRF 60 and PRF 95 $[22,23]$.

\section{RESULTS AND DISCUSSION}

All of the test points, which were investigated in the earlier parts of the experimental works, are considered and analyzed for exhaust emission level measurement. The three major regulated emissions, NOx, uHC and $\mathrm{CO}$ (carbon monoxide), are examined in accordance with three main variables (octane number and In/Ex-EGR). It is well proven that NOx formation at combustion temperatures beyond approximately $2100{ }^{\circ} \mathrm{K}$ will be 
accelerated significantly $[1,19,20,29]$. Accordingly, it can be inferred that the formation of NOx (variation of NOx) is directly proportional to the variation of $T_{\max }$ $[11,22,23,28,30]$. Thus the magnitude of $T_{\max }$ regulates the amount of NOx emission. The amount of uHC and CO emission is strictly dependent on the completion of combustion $[1,19,20,26]$. This means that the lower the incomplete combustion, the lower the uHC and $\mathrm{CO}$ emissions will be. Moreover, with prolonged combustion (i.e., higher combustion duration), the amount of $\mathrm{uHC}$ and $\mathrm{CO}$ emission can be increased considerably (mostly in the partially burned condition) [1, 9-11, 19, 20, 24, 26, 27, 29, 33].

\section{Variation in NOx Emission}

The variation in NOx concentration with the effect of the fuel octane number, In-EGR and Ex-EGR is shown in Figure 2. In the case of In-EGR application, from the slope of the curves in Figure 2(a) it can be seen that the overall trend of the NOx level is less significant when the fuel octane number is increased. However, this trend in the case of Ex-EGR application is almost constant (Figure 2(b)). Thus, at a given concentration of Ex-EGR, the NOx concentration is presumably constant. Furthermore, the variation of NOx is more sensitive to In-EGR than to Ex-EGR.

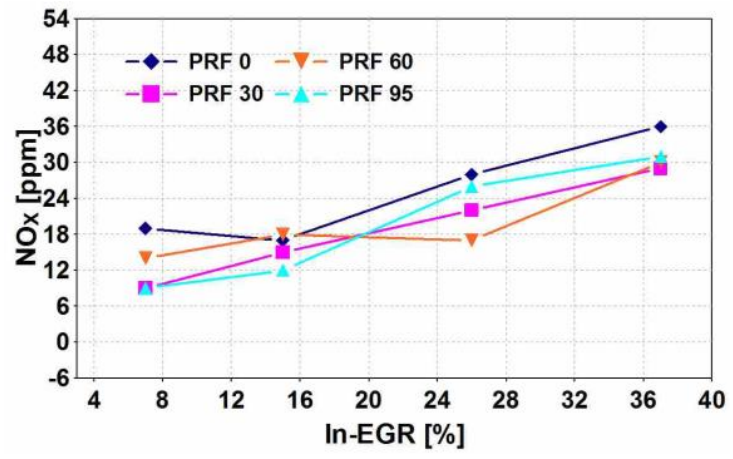

(a). NOx vs In-EGR

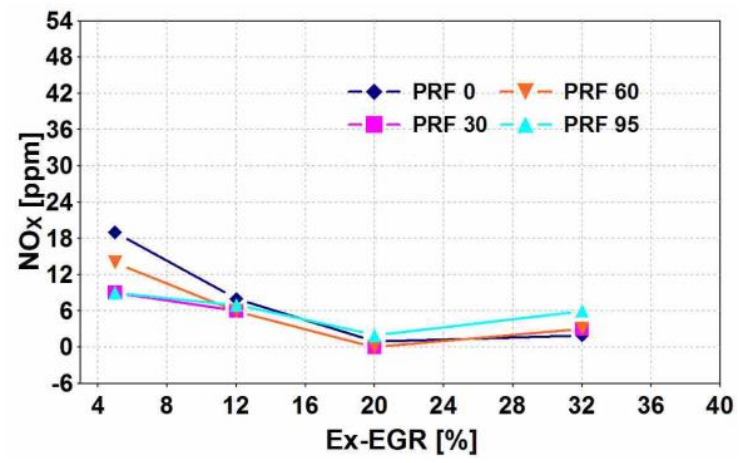

(b). NOx vs Ex-EGR

Figure 2. Variation of NOx emission due to In-EGR, Ex-EGR and octane number changes $\left[\mathrm{rpm}=2100, \mathrm{IMEP}=2.2 \mathrm{bar}, \mathrm{AFR}=15-21, T_{e p c}=530-600 \mathrm{~K}\right.$ and WOT].

Figure 2(a) explains the profiles of the NOx concentrations level with respect to the In-EGR changes. As can be clearly observed, the NOx concentration becomes higher when the percentage of In-EGR is increased. Thus, the higher the In-EGR rate, the higher the NOx concentration that will be produced. Therefore, there is a direct correlation between the variation of the In-EGR emission level and the variation of NOx. As mentioned earlier, there is no considerable tendency for variation in NOx in relation to the In-EGR changes when the fuel octane number varies. The influence of Ex-EGR on NOx concentrations is shown in Figure 2(b). The overall trend of NOx emission is downward, which implies that when the percentage of Ex-EGR rises, the NOx emission level will decrease accordingly. The higher the percentage of Ex-EGR, the lower the NOx concentration becomes. Thus it can be said that the variation of NOx emission is inversely correlated to the percentage of Ex-EGR. Apart from the test point with Ex-EGR=5\%, there is no substantial tendency for variation of NOx in relation to Ex-EGR changes when the fuel octane number varies. As clearly shown, the NOx 
concentration can be controlled appropriately by means of the fuel octane number and In/Ex-EGR regulation.

\section{Variation in uHC Emission}

The variation of uHC concentration due to the fuel octane number, In-EGR and ExEGR changes is illustrated in Figure 3(a) and Figure 3(b). As can be seen from the figures, there is no consistency in the trend of uHC variation. However, it can be seen that the level of uHC emission increases when the fuel octane number is raised. When the In-EGR percentage is set to $7 \%$ and $15 \%$, the uHC concentration seems to become constant or even decrease. Furthermore, it is inferred that the variation of uHC in relation to changes in the fuel octane number will be more substantial when the fuel octane number is at its lowest (ellipse $\mathrm{A}$ and $\mathrm{B}$ ). The effect of In-EGR on the concentration of uHC emission is presented in Figure 3(a). Generally, it can be said that the level of uHC emission will be reduced as the percentage of In-EGR is increased. However, the test points at which PRF 95 is used show a different trend. The higher the percentage of In-EGR, the lower the emission of uHC level will be. Thus there is an inverse correlation between the variation of In-EGR percentage and the variation of $\mathrm{uHC}$ concentration. Here, it is obvious that test points having higher rates of In-EGR are more likely to be influenced by changes in the fuel octane number, as is shown with the two ellipses A and B.

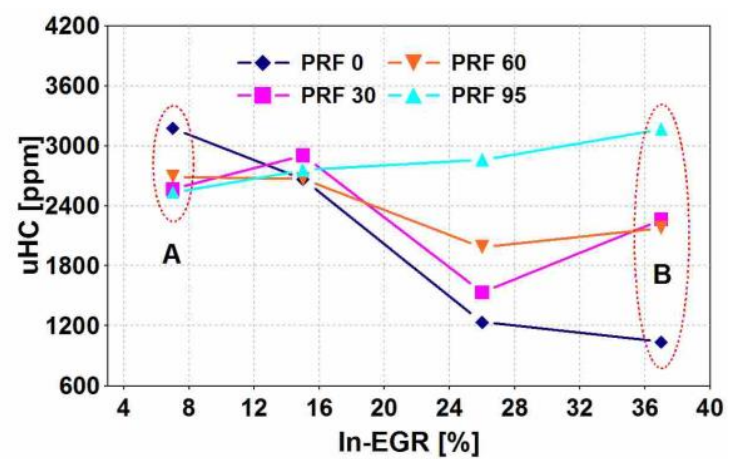

(a). NOx vs In-EGR

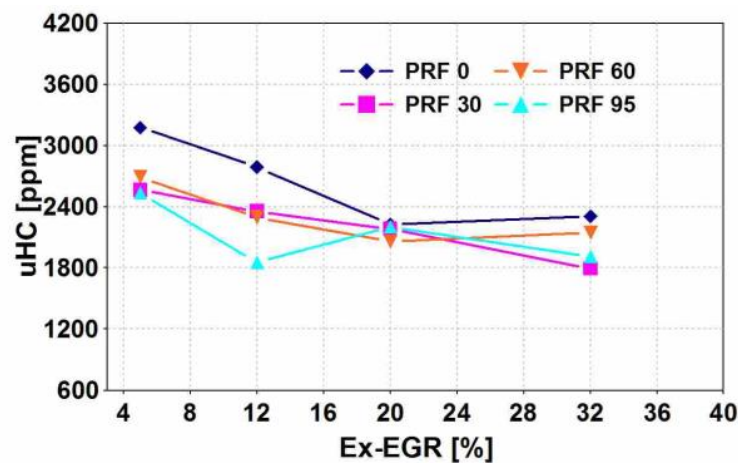

(b). NOx vs Ex-EGR

Figure 3. Variation of uHC emission in accordance with In-EGR, Ex-EGR and octane number changes $\left[\mathrm{rpm}=2100, \mathrm{IMEP}=2.2 \mathrm{bar}, \mathrm{AFR}=15-21, T_{e p c}=530-600 \mathrm{~K}\right.$ and WOT]

Figure 3 shows the relationship between the downward trends of uHC concentration due to Ex-EGR changes. The trend of the curves proves that the uHC concentration can be lowered as the concentration of Ex-EGR becomes higher. This means that the higher the rate of Ex-EGR, the lower the level of uHC emission. It is thought that because the application of Ex-EGR improves the cyclic variability of $P_{\max }$ (i.e., complete combustion), the concentration of uHC will be decreased. Thus the variation of the uHC emission level is inversely proportional to the variation of the ExEGR. There is no significant difference between the type of fuel used at each rate of ExEGR as far as the uHC emission variation is concerned. Disregarding the test point with Ex-EGR $=32 \%$ which is attributed to over-diluted Ex-EGR, the overall trend of variation for $\mathrm{uHC}$ emission is descending, meaning that as the fuel octane number is increased it will reduce the uHC concentration. Thus it seems that the higher the Ex-EGR 
concentration, the lower the uHC concentration will be. In summary, the variation of uHC concentration is inversely correlated to changes in the fuel octane number. Accordingly, it is deduced that the concentration of uHC emission can be controlled appropriately by means of the fuel octane number and In/Ex-EGR regulation.

\section{Variation in CO}

Figure 4(a) depicts the relation between CO emission and In-EGR percentage. Apart from the test points at which PRF 95 was used, the rest of the test points show the overall trend in the reduction of CO concentration. This implies that when In-EGR is increased, the level of $\mathrm{CO}$ emission will be decreased accordingly. Thus, the higher the In-EGR rate, the lower the CO emission will be. Thus it can be explained that the variation of $\mathrm{CO}$ emission is inversely proportional to the variation of the In-EGR. Furthermore, the concentration of $\mathrm{CO}$ emission is more likely to be influenced by the fuel octane number when the percentage of In-EGR is high, as is evident in ellipses A and $\mathrm{B}$. It is worth noting that when the fuel octane number is at its lowest, the variation of $\mathrm{CO}$ emission is more sensitive to changes in In-EGR, as can be seen clearly in ellipses A and B.

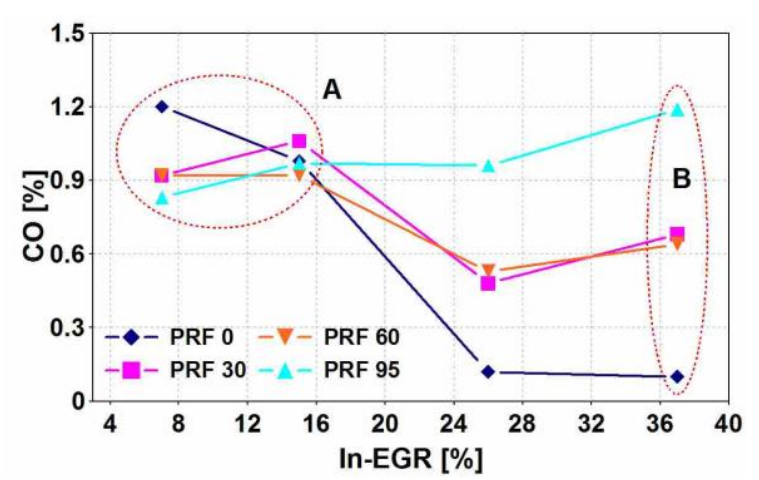

(a). NOx vs In-EGR

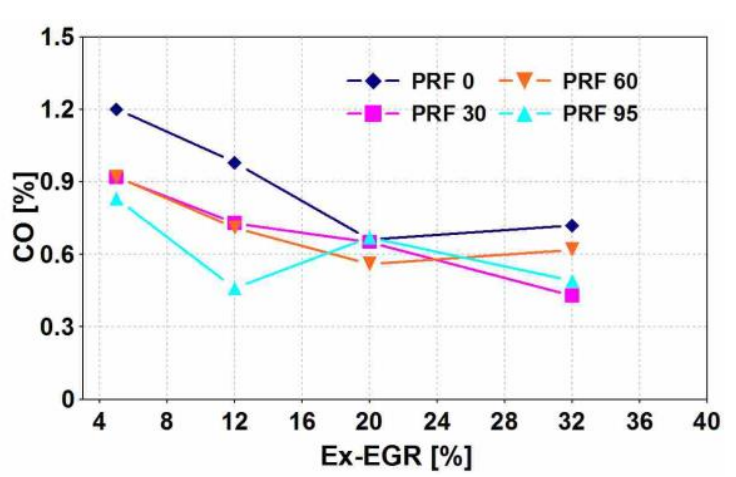

(b) NOx vs Ex-EGR

Figure 4. Variation of $\mathrm{CO}$ emission concentration due to In-EGR, Ex-EGR and octane number changes $\left[\mathrm{rpm}=2100, \mathrm{IMEP}=2.2 \mathrm{bar}, \mathrm{AFR}=15-21, T_{\text {epc }}=530-600 \mathrm{~K}\right.$ and WOT]

The influence of Ex-EGR on the variation of CO concentration is illustrated in Figure 4(b). As can be seen from the curves, the trend line of the $\mathrm{CO}$ emission level is downward, meaning that as the concentration of Ex-EGR is increased the level of CO emission will be decreased. Therefore the variation of $\mathrm{CO}$ emission is inversely proportional to the variation of Ex-EGR. Thus it is inferred that the higher the percentage of Ex-EGR, the lower the level of CO emission will become. In general, the overall trend of the $\mathrm{CO}$ emission level becomes lower as the fuel octane number is increased. In other words, the higher the fuel octane number, the lower the $\mathrm{CO}$ emission will become. It can be inferred that the variation of the $\mathrm{CO}$ emission has an inverse correlation with the variation of the fuel octane number. It can be said that across the whole range of fuel octane numbers there is no remarkable sensitivity of $\mathrm{CO}$ emission variation to the Ex-EGR changes. 


\section{CONCLUSIONS}

An experimental study was conducted to investigate the influence of In-EGR, Ex-EGR and fuel octane number on the exhaust gas emission of a CAI two-stroke cycle engine operated at constant load and speed conditions. It can be finally concluded that the fuel octane number, In-EGR and Ex-EGR offer reliable and practicable means to control the engine exhaust gas output, including the three major regulated emissions NOx, uHC and CO. Significant findings have emerged from this study and are summarized as follows:

i) The emission of NOx, uHC and NOx decreases slightly as the fuel ON increases. This is true when the In-EGR is applied.

ii) In-EGR will increase the concentration of NOx emission due to the elevated $T_{\max }$. Otherwise, the level of $\mathrm{uHC}$ and $\mathrm{CO}$ concentration will be decreased.

iii) In general, the concentrations of $\mathrm{NOx} \mathrm{uHC}$, and $\mathrm{CO}$ will reduce if the percentage of Ex-EGR is increased.

\section{ACKNOWLEDGMENTS}

The authors would like to acknowledge Universiti Teknologi Malaysia for the financial support in funding this research project (Vote No: Q.J130000.7114.02J14).

\section{REFERENCES}

[1] Zhao H. HCCI and CAI engines for the automotive industry. Woodhead Publishing; 2007.

[2] Andwari AM, Aziz AA, Said MFM, Latiff ZA. A converted two-stroke cycle engine for compression ignition combustion. Applied Mechanics and Materials. 2014;663:331-5.

[3] Andwari AM, Aziz AA, Muhamad Said MF, Abdul Latiff Z. Controlled autoignition combustion in a two-stroke cycle engine using hot burned gases. Applied Mechanics and Materials. 2013;388:201-5.

[4] Amin MA, Azhar AA. Homogenous charge compression ignition (hcci) technique: a review for application in two-stroke gasoline engines. Applied Mechanics and Materials. 2012;165:53-7.

[5] Abdullah NR, Shahruddin NS, Mamat R, Ihsan Mamat AM, Zulkifli A. Effects of air intake pressure on the engine performance, fuel economy and exhaust emissions of a small gasoline engine. Journal of Mechanical Engineering and Sciences. 2014;6:949-58.

[6] Kamil M, Rahman MM, Bakar RA. Performance evaluation of external mixture formation strategy in hydrogen fueled engine. Journal of Mechanical Engineering and Sciences. 2011;1:87-98.

[7] Kamil M, Rahman MM, Bakar RA. Integrated simulation model for composition and properties of gases in hydrogen fueled engine. International Journal of Automotive and Mechanical Engineering. 2013;8:1242-155.

[8] Kamil M, Rahman MM, Bakar RA. An integrated model for predicting engine friction losses in internal combustion engines. International Journal of Automotive and Mechanical Engineering. 2014;9:1695-708. 
[9] Asai M, Kurosaki T, Okada K. Analysis on fuel economy improvement and exhaust emission reduction in a two-stroke engine by using an exhaust valve. SAE Technical Paper No. 951764; 1995.

[10] Ishibashi Y. Basic Understanding of activated radical combustion and its twostroke engine application and benefits. SAE Technical Paper No. 2000-01-1836; 2000.

[11] Onishi S, Jo SH, Shoda K, Jo PD, Kato S. Active thermo-atmosphere combustion (ATAC) - A New combustion process for internal combustion engines. SAE Technical Paper NO. 790501. 1979.

[12] Gan S, Ng HK, Pang KM. Homogeneous charge compression ignition (HCCI) combustion: Implementation and effects on pollutants in direct injection diesel engines. Applied Energy. 2011;88:559-67.

[13] Maurya RK, Agarwal AK. Experimental investigation of cyclic variations in HCCI combustion parameters for gasoline like fuels using statistical methods. Applied Energy. 2013;111:310-23.

[14] Muhamad Said MF, Abdul Aziz A, Abdul Latiff Z, Mahmoudzadeh Andwari A, Mohamed Soid SN. Investigation of cylinder deactivation (CDA) Strategies on part load conditions within malaysian city driving operation. SAE Technical Paper No. 2014-10-13. 2014.

[15] Xie H, Li L, Chen T, Yu W, Wang X, Zhao H. Study on spark assisted compression ignition (SACI) combustion with positive valve overlap at medium-high load. Applied Energy. 2013;101:622-33.

[16] Mohanamurugan S, Sendilvelan S. Emission and combustion characteristics of different fuel In A HCCI engine. International Journal of Automotive and Mechanical Engineering. 2011;3:279-92.

[17] Yusaf T, Baker P, Hamawand I, Noor MM. Effect of compressed natural gas mixing on the engine performance and emissions. International Journal of Automotive and Mechanical Engineering. 2013;8:1416-29.

[18] Hamada KI, Rahman MM. Experimental study performance emissions small four stroke SI engine modern motorcycle. International Journal of Automotive and Mechanical Engineering. 2014;10:1852-65.

[19] Blair GP. The Basic Design of Two-stroke Engines: Society of Automotive Engineers; 1990.

[20] Heywood JB, Sher E, Engineers SoA. The two-stroke cycle engine: its development, operation, and design. New York: Taylor \& Francis; 1999.

[21] Tsuchiya K, Hirano S, Okamura M, Gotoh T. Emission control of two-stroke motorcycle engines by the butterfly exhaust valve. SAE Paper No. 800973; 1980.

[22] Andwari AM, Aziz AA, Said MFM, Latiff ZA. Experimental investigation of the influence of internal and external EGR on the combustion characteristics of a controlled auto-ignition two-stroke cycle engine. Applied Energy. 2014;134:110 .

[23] Mahmoudzadeh Andwari A, Abdul Aziz A, Muhamad Said MF, Abdul Latiff Z. An experimental study on the influence of EGR rate and fuel octane number on the combustion characteristics of a CAI two-stroke cycle engine. Applied Thermal Engineering. 2014;71:248-58.

[24] Yao M, Zheng Z, Liu H. Progress and recent trends in homogeneous charge compression ignition (HCCI) engines. Progress in Energy and Combustion Science. 2009;35:398-437. 
[25] Zeng X, Wang J. A physics-based time-varying transport delay oxygen concentration model for dual-loop exhaust gas recirculation (EGR) engine airpaths. Applied Energy. 2014;125:300-7.

[26] Zhang Y, Zhao H, Ojapah M, Cairns A. CAI combustion of gasoline and its mixture with ethanol in a 2-stroke poppet valve DI gasoline engine. Fuel. 2013;109:661-8.

[27] Asad U, Zheng M. Exhaust gas recirculation for advanced diesel combustion cycles. Applied Energy. 2014;123:242-52.

[28] Zhang Y, Zhao H, Ojapah M, Cairns A. Effects of Injection Timing on CAI Operation in a 2/4-Stroke Switchable GDI Engine. SAE International Journal of Engines. 2011;5:67-75.

[29] Zhao H, Peng Z, Ladommatos N. Understanding of controlled autoignition combustion in a four-stroke gasoline engine. Proceedings of the Institution of Mechanical Engineers, Part D: Journal of Automobile Engineering. 2001;215:1297-310.

[30] Galloni E, Fontana G, Palmaccio R. Effects of exhaust gas recycle in a downsized gasoline engine. Applied Energy. 2013;105:99-107.

[31] Fathi M, Saray RK, Checkel MD. The influence of exhaust gas recirculation (EGR) on combustion and emissions of n-heptane/natural gas fueled homogeneous charge compression ignition (HCCI) engines. Applied Energy. 2011;88:4719-24.

[32] Millo F, Giacominetto PF, Bernardi MG. Analysis of different exhaust gas recirculation architectures for passenger car Diesel engines. Applied Energy. 2012;98:79-91.

[33] Wei H, Zhu T, Shu G, Tan L, Wang Y. Gasoline engine exhaust gas recirculation - A review. Applied Energy. 2012;99:534-44.

[34] Majid ZAA. Kajian prestasi sistem pengering pam haba terbantu suria dengan pengumpul suria multifungsi. Bangi, Malaysia: Universiti Kebangsaan Malaysia; 2011. 